\title{
Evolution of Hearing
}

\author{
Rohit Mehrotra $^{1 *}$, Anubhaw ${ }^{2}$, Pankaj Srivatav ${ }^{3}$, Ujjwal Mehrotra ${ }^{4}$ and Rudresh Sharma ${ }^{5}$ \\ ${ }^{1}$ Professor of ENT, Mehrotra ENT Hospital, UP, India \\ ${ }^{2,3,4}$ Consultant, Mehrotra ENT Hospital, UP, India \\ ${ }^{5}$ Audiologist, Mehrotra ENT Hospital, UP, India
}

*Corresponding author: Rohit Mehrotra, Professor of ENT, Mehrotra ENT Hospital,

Ashok Nagar, Kanpur, UP, India.

Received Date: August 03, 2020

Published Date: October 06, 2020

\section{Introduction}

Evolution of hearing dates back to some 250 million years ago along with mammalian evolution. To understand the evolution of hearing, one needs to understand the basic mammalian evolution first. Beginning of mammal evolution first seen in Triassic period about 230 million years ago, during which all land vertebrates developed tympanic middle ear. Mammals with their various characteristic traits, arose during the Triassic period some 250 million years ago and quickly gave rise to number of separate lineages. From Triassic, evolved the jurrasic (200 million years ago) followed by the cretaceous (100 million years ago). Multituberculata (middle of lineages) formed the major group in creataceous. Cenozoic evolved from cretaceous (50 million years ago). Monotremes (egg laying mammals) forms the major group here. The THERIANS (modern mammals that does not lay eggs) split into marsupials and placentals during the cretaceous period and are the dominant creatures today.

Hearing evolution follows the ear structures evolution which started in the dryolestes (late jurrassic mammals) and continued to its present state. In other words, dryolestes were the combination for ancestral uncoiled cochlea and the neomorphic bony cochlear from which marsupials and placentals ear structures evolved. Earliest mammalian cochlea were only about $2 \mathrm{~mm}$ long and contained a lagena macula. In multituberculate and monotreme mammalian lineages, the cochlea remained relatively short and did not coil. In modern therians (placental and marsupial mammals), cochlear coiling develops, first showing in late jurassic mammals featuring 270-degree coiling and length of 3mm. High frequency hearing with fully coiled cochlea seen first in Cretaceous.
Beginning of mammal evolution first seen in Triassic period about 230 million years ago, during which all land vertebrates developed tympanic middle ear. Due to simultaneous changes in the jaw joint, number of bones at the back of jaw joint were freed and established a middle ear containing three ossicles. Multituberculates (middle of lineages), a successful group of mammals had robust middle ear bones and uncoiled short cochlea $(2-6.5 \mathrm{~mm})$ with lagenar macula. Monotremes (egg laying mammals) had uncoiled, relatively short (4.4 to $7.6 \mathrm{~mm}$ length) cochlea. Soft tissues do not fully conform to shape of bony canal and coiled in opposite direction near the tip. Middle ear is very stiff and hearing restricted to lower and middle frequencies. Audiograms were $\mathrm{V}$ shaped, centered at $5 \mathrm{KHz}$ or $\mathrm{U}$ shape with rapid loss of sensitivity below $3 \mathrm{KHz}$ and above $16 \mathrm{KHz}$. Presence of lagenar macula at apical end of monotreme cochlear canal correlate with its likely presence in multituberculate cochlea at one end and with modern avian and reptilian cochleae at other end.

Coiling of cochlea is for efficient innervations and blood supply. Elongation of cochlea is related with increasing resolution of sound frequency. Curved gradient of coiled cochlea focuses acoustic energy towards apex (most sensitive for lower frequency). These new changes are related with earliest diversification of metatherians and eutherians in cretaceous leading to increase hearing in cenozoic and living marsupids and placentals. First report of coiled cochlea was seen in Dryolestes leiriensis (late Jurrasic mammal), 150-millionyear-old fossil in Cladotheria clade. Dryolestes are near relative to modern marsupials and mammals. Detailed evolution of inner and middle ear as well as auditory pathways are explained below. 


\section{Evolution of Inner Ear Structures}

The earliest mammalian cochlea were smooth bony walled canals with no firm contact to soft tissue. In late jurrasic fossil mammalian cochlea, bony canal became integrated into soft tissue. Both primary and secondary laminae were present supporting the inner and outer edges of basilar membrane and cochlear ganglion was enclosed within the bony wall. Nerve fibres pass through the clear openings in the bone to enter organ of corti. The development of primary osseous spiral lamina probably resulted from coiling of cochlear canal.

Thus during the Jurassic, the ancestors in therian mammal lineage increase the length of their cochlea moderately, continued the partial coil, integrate soft and bone tissues and reduce the number of cells across the organs The eventual loss of lagena macula from cochlear apex at some time during the cretaceous enabled therian mammals to reduce calcium concentration in cochlear endolymph to micromolar levels leading to evolution of tectorial membrane (which was highly sensitive to ionic environment), mechanosensory channels of hair cells and perhaps the properties of Prestins. The evolution of acetylcholine receptor systems that controls the outer hair cells afferent feedback correlates with evolution of prestins in therians. Prestins gradually evolved into more effective components of motor system specialized for effects in a useful range of cell potentials.

The earliest land vertebrates had an auditory papilla that rested on solid tissue and had an otolith covering. In amphibians, the otolithic membrane was replaced by tectorial covering free of otoliths. In all the following lineages, freely suspended basilar membrane originated. In other lineages, the basilar membrane showed partial tuning, with only moderate frequency selectivity. Only in Therian lineage did a bony support system originate for basilar membrane which was later accompanied by sharp frequency selectivity of oscillations of basilar membrane /organ of corti complex.

First report of coiled cochlea was seen in Dryolestes leiriensis (late Jurrasic mammal), 150-million-year-old fossil in Cladotheria clade. Dryolestes are near relative to modern marsupials and mammals. Cochlea is $3.3 \mathrm{~mm}$ long and 270 degree coiled. Bony interior structure was the newer development seen different from the primitives ones. CT scans showed the presence of curved track of fine cochlear foramina with each foramina being a separate entrance of individual fascicle of cochlear nerve (Foramina forms sieve like cribriform plate in internal acoustic meatus in marsupials).

In Dryolestes, primary bony lamina and its associate ganglion canal extend along basal half turn (180 degree) of cochlear canal but not reaching apical quarter cochlear turn whereas in marsupials and placentals, the primary bony canal reach to apex of entire coiled cochlea. The more primitive cochlea was a simple tube, straight or slightly curved, with a single large opening for cochlear nerve in internal acoustic meatus, without any interior bony structures for cochlear innervations. Difference with Monotremes was the presence of bony cochlear ganglion canal and primary bony lamina for nerve fibres in Dryolestes. Similarity being the presence of cochlear nerve foramina of sieve-like cribriform plate. Hence Dryolestes were the combination for ancestral and uncoiled cochlear canal and the neomorphic bony feature of cochlear innervations, from which the more derived and sophisticated ear structures of marsupials and placentals developed.

STRIP 2 (Striatin interacting protein 2) plays a functional role in the first synapse between inner hair cells and nerve fibres. When at the cochlear sensory epithelium, they found a significant reduction in auditory nerve synapses. STRIP 2 underwent strong positive selection in mammalian lineage and played important role in inner ear physiology. Extensive evolutionary remodeling that this gene underwent in mammalian linage provided an adaptive value. Genes responsible for changes were Neurogenin-1 (Ngn 1) for the progenitor determination of ganglion neurons, Neuro D(neurod1) for forming and maintaining the ganglion neurons, brain derived neurotrophic factors (BDNF) and neurotrophin 3 (NT3) for supporting the ganglionic innervations to hair cells. According to phylogeny, formation of cochlear ganglion by co-option of such genes and genes for related epithelio mesenchyme interaction, had occurred first in evolution in Cladotherian clade in the middle Jurrassic.

\section{Changes in Middle Ear}

Early vertebrates had an otic structure, indicating the presence of stapes in the matrix of posterior underside of skull. Stapes forms the only link between palate and otic region of brain case. Palate was potentially mobile and was involved with buccal ventilation. When the palate bone was released from this role by development of alternative mechanisms, stapes could specialize as purely auditory ossicle. Further adaptations for eating, including versatile jaw movements and more precise dental occlusion, have been interpreted as directly setting the stage for mammalian adaptation of posterior of posterior jaw bones for hearing. Over millions of years, bones with integral part of jaw support system in early reptiles, lost their eating function as reptilian jaw foreshortened with new articulation leading to reduction in size and form the three bone ossicular chain common in modern mammalian middle ear.

Early mammal tympanic middle ear was restricted to poor sensitivity and to low frequency, derived by presence of very short papillae, the stapes size, bony component connecting quadrate to inner ear and connection of middle ear to lower jaw. Malleus remained attached to lower jaw. In early mammal Morganucodon, the middle ear had function in jaw support and was not sufficiently evolved to be termed as transitional middle ear. For the first half of evolutionary history, mammals did not hear high frequencies. In Monotremes and multituberculates, upper limit remained below $20 \mathrm{KHz}$ and gradual increase in upper limit of hearing to 
$20 \mathrm{KHz}$. After full coiling of cochlea achieved, middle ear evolved to freely suspended form of therians and Prestins evolution was a significant leap forward, high frequency hearing evolved and today represented in therian cochlea with length between $7 \mathrm{~mm}$ (mouse) and $>50 \mathrm{~mm}$ (blue whales).

\section{Auditory Pathway Changes}

Humans had the smallest auditory system per brain size, owing to large brain size compared to auditory system. This small ratio was secondary result of expansion of other, non-auditory parts of brain with expanded occipital and temporal lobes. Medial olivary nucleus, part of superior olivary complex is relatively large in humans than in cats and other mammals, due to potential, based on large head size, for localization of sound by inter aural analysis of low frequencies. In contrast, greatest development of lateral olivary nucleus occurs in echolating mammals, bats and porpoises but remains smaller in primates, monkeys and apes owing to be related to limited range of audible frequencies, particularly in higher ranges. In echolating animals, large size of nucleus serves as hearing range extending over $100 \mathrm{KHz}$. The reduction in humans correlates with high frequency limit at approximately $18 \mathrm{KHz}$.

Small cell cap of the cochlear complex in comparison to all other nuclei, showed pronounced reduction in humans as an implication of less diversity and complexity in auditory processing at subcollicular levelin human brain. These reductions viewed as biological adaptation of auditory system. Earliest mammals exploited nocturnal niches, which were relatively free of large, diuran reptiles and therefore, hearing and smell were more useful at night than vision. This lead to development other adaptation of homoiothermy (constant internal body temperature) for better heat retention at night, with superficial insulation which required a high sustained activity level, accompanied by stable metabolism rate. This in turn required regular efficient ingestion of food leading to continous changes in dental and jaw morphology and articulation, further leading to changes in middle and inner ear.

\section{Human Hearing Evolution}

Five parameters of hearing-high frequency cutoff, low frequency sensitivity, lowest threshold, best frequency and total area of audible field were compared and studied.

\section{High frequency hearing}

Range of high frequency hearing extends from a low near 18 $\mathrm{KHz}$ for man to about $120 \mathrm{KHz}$ for dolphin and bat. The striking difference in upper limits of frequency is due to presence of ossicular linkage in middle ear of mammals. Amphibians, reptiles and birds have only single functional bone in middle ear for sound conduction from tympanic membrane to cochlea (columella or stapes) and three bones in lower jaw (dentary, angular and articular) whereas mammals have three bones in middle ear and one in lower jaw(dentary). Ossicular linkage acts as simple lever providing mechanical transformation that matches impedance of air to cochlear fluid impedance. Since high frequency vibrations require this matching of impedance, hence evolution of middle ear ossicles was detrimental for radical difference in upper limit of hearing between mammals and non-mammals.

Selective pressure for accurate sound localizations have been the driving force behind the final stage in evolution of mammalian variety of middle ear. In man evolution, from the early Eocene onward, progressively wider set ears released man's ancestors from selective pressure for high frequency hearing resulting in regression of upper limit. Mammals that have small binaural time disparities, either because of close set ears or marine environment, increase their accuracy in localizing sound source by maximizing the availability of binaural spectra disparities which in turn is through sensitivity to high frequency. High frequency hearing is a result of selective pressure for accurate and instantaneous localization of source of brief sounds.

\section{Low frequency sensitivity}

1. It is not a primitive mammalian character.

2. Animals in man's line of descent showed marked improvement in low frequency hearing.

3. Increase in low frequency sensitivity, though almost linera across the phyletic sequence, was probably not steady in time.

4. Low frequency hearing improved slowly until the Paleocene, then quickly through the Eocene- then remained unchanged till present.

\section{Lowest threshold}

1. Large differences in general sensitivity among animals occur between levels at lowest stages (i.e. opossum-hedgehogtree shrew levels phyletically; cretaceous to Paleocene, historically). This difference might be related to rigidity of tympanic suspension. The ring of bone (ectotympanic) that supports eardrum is incomplete in opossum and more complete in tree shrew. This progressive encirclement of tympanum is accompanied by development of sturdy auditory bulla. Lack of this rigid support for tympanic membrane in primitive mammals results in loss of energy during first link in transmission of air movements to cochlear fluids and resultant insensitivity.

2. Frequency of lowest threshold has declined in man's lineage- the greatest drop probably occurring during the Eocene.

\section{Best frequency}

1. High frequency hearing is related to direct effect of selective pressure for accurate sound localization. Animals with a high best frequency always have a high upper limit of hearing, and animals with high upper limit usually have a high best frequency. 
2. The uniquely mammalian capacity for high frequency hearing is probably the result of selective pressure for sound localization.

\section{Area of audible field}

1. Average audible field of mammals is larger than birds and reptiles owing to mammalian capacity for high frequency hearing.

2. Man's ancestors gradually attained more extensive audible fields by increasing their sensitivity to low frequency until the focene. Since that time the audible field has slightly regressed due to loss of high frequency hearing.

3. The total area of audible field increased until the Eocene and has decreased since then. The increase at early stages was due to increase in low frequency sensitivity while the high frequency remains unchanged. The decrease at later stages was due to loss of high frequency sensitivity while low frequency sensitivity remained unchanged.

\section{The Lineage of Modern Amniotes and Characteristic Hearing Organ Morphologies}

Four basic types of amniote ear refer to mammalian, avian, lizards and turtle. Except for turtles all groups developed sensitivity to high frequencies.

Turtles have the least specialized hearing organ, resembling early stem reptiles. Hair cells are unspecialized, innervated by both afferent and efferent nerve fibres and respond to low frequencies. The stereovillar bundles of all hair cells are uniformly oriented with weak morphological gradients. The ion channel compliment of hair cell membranes create electrical resonances at preferred frequencies. The basilar papilla was the first hair cell organ to form over a moveable membrane (basilar membrane, BM). BM shows no special frequency selectivity in turtles and lizards. Lizard auditory epithelia varies from $<100$ micrometers to $>2 \mathrm{~mm}$ and in number of hair cells from $<60$ to $>2000$. Hair cells may be covered by a continuous tectorial membrane (TM), by a TM that is divided into chain of sallets, or have no TM at all. Lizard papillae show two hair cell types. One papillar area contain hair cells with greater basal diameter, large numbers and larger afferent nerve fibres and an efferent innervations. All have same (abneural) orientation. Functionally, these cells respond to low frequencies (below about 1 $\mathrm{KHz}$ ). The second type is smaller in size, smaller and fewer afferents, and complete lack of an efferent innervations. All have groups of neurally and abneurally oriented hair cell bundles (bidirectional orientation). Cells respond to frequency above $1 \mathrm{KHz}$, with an upper limit of $4 \mathrm{KHz}$ and micromechanically tuned. Evolution of tympanic middle ear initiated the development of high frequency hair cell areas of stem lizards.

Birds and mammals: Both have specialized hair cell populations located across the width of papilla, essentially at all frequency locations and within a continuous tonotopic organization. Both groups have independently-developed responses to high frequency, in some birds upto $10 \mathrm{KHz}$, in some mammals even beyond 100 KHz. Papillar elongation was generally more extensive than the maximum of $2 \mathrm{~mm}$ in lizards. Owl papillae reach $11 \mathrm{~mm}$ and whale papillae $105 \mathrm{~mm}$. the coiled cochlea, which evolved after divergence of marsupial placental line in late Mesozoic, was a mechanism of accommodating a long papilla. In mammals, basilar membrane frequency selectivity is identical to that of inner hair cells and afferent fibres. Response is feature of entire organ, and no component is separable without reducing sensitivity and selectivity. This linking is not well developed in birds because the hair cells that connect to most of the afferent fibers are not over free BM, but over the limbus.

To summarise, it can be said that most important changes in cochlear mechanisms during phylogeny were initiated by changes in middle ear. This led to predominance on micromechanical tuning, a profound elongation of papilla, and the specialization of hair cells to generate a division of labor in birds and mammals.

\section{Conclusion}

Evolution of hearing started 250 million years ago along with mammalian evolution and continued during the human evolution. Inner ear structures as well as middle ear structures continued to evolve to its present state in humans and other vertebrates. Simultaneously hearing also evolved correlating with the changes in ear structures. Thus, three parallel series of development over 150 million years ago led to high frequency hearing only in most modern therian cochleae:

1. The initially stiff middle ear gradually became lighter and more freely suspended.

2. The initially very short cochlea was gradually elongated and the soft tissues incorporated bony support elements of basilar membrane and thus better matched the middle ear impedance. The cochlea coiled and eliminated the lagena macula.

3. Prestins gradually evolved into more effective motor system components specialized for effects in a useful range of cell potentials with further specialization in late evolving echolating species.

\section{Acknowledgement}

None.

\section{Conflict of Interest}

No conflict of interest.

\section{References}

1. Aitkin LM, Johnstone BM (1972) Middle-ear function in a monotreme: the echidna (Tachyglossus aculeatus). J Exp Zool 180: 245-250.

2. Armstrong SD, Bloch JI, Houde P, Silkox MT (2011) Cochlear labyrinth volume in euarchontoglirans: implications for the evolution of hearing in primates. Anat Rec 294: 263-266. 
3. Beurg M, Nam JH, Chen Q, Fettiplace R (2010) Calcium balance and mechanotransduction in rat cochlear hair cells. J Neurophysiol 104: 1834.

4. Bininda-Emons ORP, Cardillo M, Jones KE, MacPhee RDE, Beck RMD, et al. (2007) The delayed rise of present-day mammals. Nature 446: 507 512.

5. Christensen-Dalsgaard J (2010) Vertebrate pressure-gradient receivers. Hear Res 273: 37-45.

6. Clack JA (2002) Patterns and processes in the early evolution of the tetrapod ear. J Neurobiol 53: 251-264.

7. Coleman MN, Boyer DM (2012) Inner ear evolution in primates through the Cenozoic: implications for the evolution of hearing. Anat Rec 294 615-631.

8. Elgoyhen AB, Franchini LF (2011) Prestin and the cholinergic receptor of hair cells: positively-selected proteins in mammals. Hear Res 273: 100-108.

9. Evans AR, Jones D, Boyer AG, Brown JH, Costa DP, et al. (2012) The maximum rate of mammal evolution. Proc Natl Acad Sci U S A 109: 41874190 .

10. Fleischer G (1978) Evolutionary principles of the mammalian middle ear. Adv Anat Embryol Cell Biol 55: 3-70

11. Fox RC, Meng J (1997) An X-radiographic and SEM study of the osseous inner ear of multituberculates and monotremes (Mammalia) implications for mammalian phylogeny and evolution of hearing. Zool J Linn Soc 121: 249-291.

12. Franchini LF, Elgoyhen AB (2006) Adaptive evolution in mammalian proteins involved in cochlear outer hair cell electromotility. Mol Phylogenet Evol 41: 622-635.

13. Gates GR, Saunders JC, Bock GR, Aitkin LM, Elliot MA (1974) Peripheral auditory function in the platypus, Ornithorhynchus anatinus. J Acoust Soc Am 56: 152-156.

14. Gavara N, Manoussaki D, Chadwick RS (2011) Auditory mechanics of the tectorial membrane and the cochlear spiral. Curr Opin Otolaryngol Head Neck Surg 19: 382-387.

15. Greybeal A, Rosowski JJ, Ketten DR, Crompton AW (1989) Inner-ear structure in Morganucodon, an early Jurassic mammal. Zool J Linn Soc 96: 107-117.

16. Heffner RS, Koay G, Heffner HE (2001) Audiograms of five species of rodents: implications for the evolution of hearing and the perception of pitch. Hear Res 157: 139-152.

17. Hemilä S, Nummela S, Reuter T (1995) What middle ear parameters tell about impedance matching and high frequency hearing. Hear Res 85 31-44.

18. Hudspeth AJ (2008) Making an effort to listen: mechanical amplification in the ear. Neuron 59: 530-545.

19. Hurum JH (1998) The inner ear of two Late Cretaceous multituberculate mammals, and its implications for multituberculate hearing. J Mamm Evol 5: 65-93.

20. Ji Q Luo ZX, Yuan CX, Wible JR, Zhang JP, et al. (2002) The earliest known eutherian mammal. Nature 416: 816-822.

21. Kemp TS (2005) The origin and evolution of mammals. Oxford University Press, Oxford, USA.

22. Kemp TS (2007) Acoustic transformer function of the postdentary bones and quadrate of a nonmammalian cynodont. J Vert Paleontol 27: 431-441

23. Köppl C, Forge A, Manley GA (2004) Low density of membrane particles in auditory hair cells of lizards and birds suggests an absence of somatic motility. J Comp Neurol 479: 149-155.

24. Kronester Frei A (1979) The effect of changes in endolymphatic ion concentrations on the tectorial membrane. Hearing Research 1: 81-94.

25. Ladhams A, Pickles JO (1996) Morphology of the monotreme organ of corti and macula lagena. J Comp Neurol 366: 335-347.
26. Lavender D, Taraskin SN, Mason MJ (2011) Mass distribution and rotational inertia of "microtype" and "freely mobile" middle ear ossicles in rodents. Hearing Research 282: 97-107.

27. Li Y, Liu Z, Shi P, Zhang J (2010) The hearing gene prestin unites echolocating bats and whales. Curr Biol 20: R55-R56.

28. Liu Y, Cotton JA, Shen B, Han X, Rossiter SJ, et al. (2010) Convergent sequence evolution between echolocating bats and dolphins. Curr Biol 20: R53-R54.

29. Luo ZX (2007) Transformation and diversification in early mammal evolution. Nature 450: 1011-1019.

30. Luo Z, Ketten DR (1991) CT scanning and computerized reconstructions of the inner ear of multituberculates mammals. J Vert Paleontol 11: 220 228.

31. Luo Z-X, Ruf I, Schultz JA, Martin T (2010) Fossil evidence on evolution of inner ear cochlea in Jurassic mammals. Proc Roy Soc B 278: 28-34.

32. Manley GA (1972) Frequency response of the middle ear of geckos. J Comp Physiol 81: 251-258

33. Manley GA (1973) A review of some current concepts of the functional evolution of the ear in terrestrial vertebrates. Evolution 26: 608-621.

34. Manley GA (1990) Peripheral hearing mechanisms in reptiles and birds. Springer, Heidelberg.

35. Manley GA, Clack JA (2004) An outline of the evolution of vertebrate hearing organs. In: Manley GA, Popper A, Fay RR (Eds,) Evolution of the vertebrate auditory system. Springer, New York, USA, p: 1-26.

36. Martin T, Luo ZX (2005) Homoplasy in the mammalian ear. Science 307: 861-862.

37. Masterton B, Heffner H, Ravizza R (1969) The evolution of human hearing. J Acoust Soc Amer 45: 966-985.

38. McGowan MR, Spaulding M, Gatesy J (2009) Divergence date estimation and a comprehensive molecular tree of extant cetaceans. Molecular Phylogenetics Evolution 53: 891-906.

39. McGowan MR (2011) Towards a resolution of an explosive radiation-a multilocus phylogeny of oceanic dolphins (Delphinidae). Molecular Phylogenetics and Evolution 60: 345-357.

40. Meng J, Fox RC (1995) Therian petrosals from the Oldman and Milk River formations (Late Cretaceous), Alberta, Canada. J Vert Paleontol 15: 122-130.

41. Meng J, Wang Y, Li C (2011) Transitional mammalian middle ear from a new Cretaceous Jehol eutriconodont. Nature 472: 181-185.

42. Mills DM, Shepherd RK (2001) Distortion product otoacoustic emission and auditory brainstem response in the echidna (Tachyglossus aculeatus). J Assoc Res Otolaryngol 2: 130-146.

43. Müller M, Laube B, Burda H, Bruns V (1992) Structure and function of the cochlea in the African mole rat (Cryptomys hottentotus): evidence for a low frequency acoustic fovea. J Comp Physiol A 171: 469-476.

44. Novacek MJ (1977) Aspects of the problem of variation, origin and evolution of the eutherian auditory bulla. Mamml Rev 7: 131-149.

45. Nummela S, Thewissen JGM, Bajpai S, Hussain T, Kumar K (2007) Sound transmission in archaic and modern whales: anatomical adaptations for underwater hearing. Anat Rec 290: 716-733.

46. Plassmann W, Brindle K (1992) A functional model of the auditory system in mammals and its evolutionary implications. In: Webster DB, Fay RR, Popper AN (Eds,). The evolutionary biology of hearing. Springer, New York, USA, pp: 637-653.

47. Puria S, Steele C (2010) Tympanic-membrane and malleus-incuscomplex co-adaptations for high-frequency hearing in mammals. Hear Res 253: 183-190.

48. Ravicz ME, Slama MCC, Rosowski JJ (2010) Middle-ear pressure gain and cochlear partition differential pressure in chinchilla. Hear Res 263: 16- 
49. Rich TH, Hopson JA, Musser AM, Flannery TF, Vickers-Rich P (2005) Independent origins of middle ear bones in monotremes and therians. Science 307: 910-914.

50. Rosowski JJ (1992) Hearing in transitional mammals: predictions from the middle-ear anatomy and hearing capabilities of extant mammals. In: Webster DB, Fay RR, Popper AN (Eds,). The evolutionary biology of hearing. Springer, New York, USA, pp: 615-631.

51. Rosowski JJ, Graybeal A (1991) What did Morganucodon hear? Zool J Linnean Soc 101: 131-168.

52. Rowe T (1988) Definition, diagnosis, and origin of Mammalia. J Vert Paleontol 8: 241-264.

53. Ruf I, Luo ZX, Wible JR, Martin T (2009) Petrosal anatomy and inner ear structures of the late Jurassic Henkelotherium (Mammalia, Cladotheria, Dryolestoidea): insight into the early evolution of the ear region in cladotherian mammals. J Anat 214: 679-693.

54. Ruggero MA, Temchin AN (2002) The roles of the external, middle, and inner ears in determining the bandwidth of hearing. PNAS 99: 1320613210.

55. Schmitz L, Motani R (2011) Nocturnality in dinosaurs inferred from scleral ring and orbit morphology. Science 332: 705-708.

56. Shoshani J, McKenna MC (1998) Higher taxanomic relationships among extant mammals based on morphology, with selected comparisons of results from molecular data. Molecular Phylogenetics and Evolution 9: 572-584.

57. Sim JH, Puria S (2008) Soft tissue morphometry of the malleus-incus complex from micro-CT imaging. J Assoc Res Otolaryngol 9: 5-21.

58. Simmons NB, Seymour KL, Habersetzer J, Gunnell GF (2008) Primitive Early Eocene bat from Wyoming and the evolution of flight and echolocation. Nature 451: 818-821.

59. Takechi M, Kuratani S (2010) History of studies on mammalian middle ear evolution: a comparative morphological and developmental biology perspective. J Exp Zool (Mol Dev Evol) 314B: 417-433.
60. Tan X, Pecka JL, Tang J, Okoruwa OE, Zhang Q et al. (2011) From zebrafish to mammal: functional evolution of prestin, the motor protein of cochlear outer hair cells. J Neurophysiol 105: 36-44.

61. Vater M, Meng J, Fox RC (2004) Hearing organ evolution and specialization: early and later mammals. In: Manley GA, Popper A, Fay RR (Eds,). Evolution of the vertebrate auditory system. Springer, New York, USA, pp: 256-288.

62. Wang Y, Hu Y, Meng J, Li C (2001) An ossified Meckel's cartilage in two Cretaceous mammals and origin of the mammalian middle ear. Science 294: 357-361.

63. Watson DMS (1953) The evolution of the mammalian ear. Evolution 7: 159-177.

64. West CD (1985) The relationship of the spiral turns of the cochlea and the length of the basilar membrane to the range of audible frequencies in ground dwelling mammals. J Acoust Soc Amer 77: 1091-1101.

65. Wible JR (1990) Petrosals of Late Cretaceous marsupials from North America, and a cladistic analysis of the petrosals in therian mammals. J Vert Paleontol 10: 183-205.

66. Wible JR (1991) Origin of Mammalia: the craniodental evidence reexamined. J Vert Paleontol 11: 1-28.

67. Wible JR, Rougier GW, Novacek MJ, McKenna MC (2001) Earliest eutherian ear region: a petrosal referred to Prokennalestes from the early Cretaceous of Mongolia. Amer Mus Nov 3322: 1-44.

68. Woodburne MO, Rich TH, Springer MS (2003) The evolution of tribospheny and the antiquity of mammalian clades. Mol Phylogenet Evol 28: 360-385.

69. Zhou X, Xu S, Yang Y, Zhou K, Yang G (2011) Phylogenomic analyses and improved resolution of Cerartiodactyla. Molecular Phylogenetics and Evolution 61: 255-264. 